\title{
Engineering Education: Problems of Modernization in the Context of a Competence Approach
}

\author{
https://doi.org/10.3991/ijep.v10i6.14043 \\ Negmatzhan Almetov \\ M. Auezov South Kazakhstan State University, Shymkent, Kazakhstan \\ Ainur Zhorabekova ${ }^{(\varpi)}$ \\ International University of Tourism and Hospitality, Turkistan, Kazakhstan \\ ainur-zhorabekova@mail.ru \\ Ibragim Sagdullayev \\ H. A. Yasawi International Kazakh-Turkish University, Turkistan, Kazakhstan \\ Zhanar Abilhairova \\ Korkyt Ata Kyzylorda State University, Kyzylorda, Kazakhstan \\ Kholidin Tulenova \\ S. Seifullin Kazakh Agrotechnical University, Astana, Kazakhstan
}

\begin{abstract}
The complex issues of engineering education in a modern university are highlighted in this study from the perspective of the implementation of a competence-based approach. It is worth noting that the development of future basic professional competencies for engineers within a university context requires updating the content of higher education in transition areas with emphasis on results. There is also an opinion that today many characteristics of engineering education need to be improved. However, education in engineering, despite many developments, still falls short of the level of economic, scientific, technical, social, and cultural targets that are required for it to be effective. A defined set of problems for training future engineers in the context of the competency approach are therefore identified here: fundamentalization of the content of engineering education and improving its intellectualization; the formation and development of student engineering creativity; the development of ecological thinking; a humanization of the content of engineering education, and; professional skills and personal self-development for future engineers. These related problems require innovative approaches and solutions to the development of the content and organization of educational process in the preparation of the future engineers at university. The aim of the study is to determine the basic professional competencies of the future engineer and, on this basis, to identify and characterize the fundamental directions and ways of modernizing the content of engineering and technical education in higher education. The research is based on a survey of students and teachers of engineering specialties of M. Auezov South Kazakhstan State University, analysis of study programs and academic planning documentation of universities, theoretical analysis of references on the issues of engineering
\end{abstract}


education, pedagogical modeling of the content of engineering education based on a competency-based approach.

Keywords - Engineering education, competence approach, professional competencies, future engineer, engineering activities

\section{Introduction}

Training engineers for new developments that correspond to the realities and expectations of modern production characterized by constant changes under the influence of factors and conditions of the post-industrial society is necessary; students need to develop a clear theoretical understanding in order to identify real-world problems, and the solutions to this issue depends largely on the success of university education in this area. We are currently observing a number of factors and conditions that have an impact on production processes, and, of course, on the level of development of engineer professional competencies across various industries. Issues include:

- The growth of knowledge-intensive production, i.e., real needs of production processes for new, reliable scientific knowledge

- The computerization of production processes and the introduction of new information technologies

- The movement of human capital, new equipment and technology in connection with integration processes within the territories of European Union and the Eurasian Economic Community

- Constant fluctuations in the prices of raw materials, goods and services, unstable main levers of economic growth

- The growth of cultural production

- Strengthening of requirements for the development of human capital

- Improvement of the legislative, legal and regulatory framework of industrial, engineering activity

- Strengthening environmental requirements for the industrial activity

- Complications in psychological and humanitarian aspects of industrial activity.

The implementation and strengthening of the competency-based approach to training future engineers is determined by the needs of the labor market, the requirements of employers for the content and quality of training of future engineers. When drawing up questionnaire questions, we took into account that employers "tell" the developers of study programs what kind of engineer should be according to their ideas, what competencies he should have, what to teach the student - the future engineer at the university. However, the employer is a practitioner; he cannot give all the wording necessary for developers of study programs. His opinions require further "pedagogical processing". It is difficult to be able to "hear" all the answers we need from the employer. Therefore, we used questionnaires with possible answers.

A survey of employers from among the enterprises and organizations of the city of Shymkent shows the following picture (Table 1): 
Table 1. Opinions of employers regarding the modernization of the content of engineering education at a university

\begin{tabular}{|c|c|c|}
\hline No & Questions & Employers' responses \\
\hline 1. & $\begin{array}{l}\text { How are you satisfied with the quality of } \\
\text { engineering training at the university? }\end{array}$ & $\begin{array}{l}\text { "Satisfied" - 55\% } \\
\text { "Less Satisfied" - 32\% } \\
\text { "Not satisfied" - } 13 \%\end{array}$ \\
\hline 2. & $\begin{array}{l}\text { What is the reason for your satisfaction } \\
\text { /dissatisfaction of the content of future } \\
\text { engineer training at the university? }\end{array}$ & $\begin{array}{l}\text { 2.1. Graduates lack practical skills - } 71 \% \\
\text { 2.2. Graduates are at a loss for solving mental professional } \\
\text { tasks - } 57 \% \\
\text { 2.3. Graduates are hard to adapt in production conditions - } \\
66 \% \\
\text { 2.4. Graduates do not know how to work in the team - } 80 \% \\
\text { 2.5. Graduates have poorly developed communication } \\
\text { skills - } 77 \% \\
\text { 2.6. Graduates are difficult to master innovation - } 68 \%\end{array}$ \\
\hline 3. & $\begin{array}{l}\text { What do we need to pay attention for in } \\
\text { preparing study programs for engineering } \\
\text { specialties? }\end{array}$ & $\begin{array}{l}\text { 3.1. On definition and formulation of professional } \\
\text { knowledge and skills - } 66 \% \\
\text { 3.2. For the formation of basic competencies - 59\% } \\
\text { 3.3. On the formation of special competencies - } 79 \%\end{array}$ \\
\hline 4. & $\begin{array}{l}\text { What directions of modernization of the } \\
\text { content of study programs of engineering } \\
\text { specialties do you consider the most rele- } \\
\text { vant today? }\end{array}$ & $\begin{array}{l}\text { 4.1. Correspondence of engineering education to the level } \\
\text { of economic, scientific, technical, social and cultural devel- } \\
\text { opment of society - } 92 \% \\
\text { 4.2. Fundamentalization of the content of engineering edu- } \\
\text { cation - } 67 \% \\
\text { 4.3. Increasing the level of its intellectualization - } 55 \% \\
\text { 4.4. Formation and development of engineering creativity - } \\
\text { 45\% } \\
\text { 4.5. Development of environmental thinking - } 39 \% \\
\text { 4.6. Humanitarian education - } 33 \% \\
\text { 4.7. Development of skills of professional and personal } \\
\text { self-development of future engineers - } 78 \%\end{array}$ \\
\hline 5. & $\begin{array}{l}\text { How do you imagine the prospects of en- } \\
\text { gineering education that we need to con- } \\
\text { sider for the advanced training of engi- } \\
\text { neering students? }\end{array}$ & $\begin{array}{l}\text { 5.1. Development of dual education - } 80 \% \\
\text { 5.2. Research focus of engineering education - 51\% } \\
\text { 5.3. Universalization of engineering specialties (training of } \\
\text { general engineers) - 73\% } \\
\text { 5.4. Priority of a competency approach - } 89 \% \\
\text { 5.5. Flexibility of study programs - } 85 \%\end{array}$ \\
\hline
\end{tabular}

The data from the survey of employers shows that, for the most part, employers note the need to modernize the content of engineering education in the direction of formation and development of basic, universal competencies of students - future engineers, despite the priority given to graduates readiness in a special specialized aspect.

\section{Methods}

The research methods used here include the study and analysis of engineering education problems from a competence-based approach perspective. These approaches were developed via the use of complex scientific and pedagogical research methods including the analysis of university documents, investigation and analysis of psychological and educational literature, pedagogic modeling of modern engineer professional competencies, and a systematic and comprehensive methodology approaches to the 
study of engineering education practice. The conclusions and recommendations presented here are based on the system analysis and synthesis of best practices as well as the innovative university training of future engineers in Kazakhstan. This study has a number of design prospects for improvement because it solves complex organizational and pedagogical issues.

\section{Results}

A number of factors determine the requirements of modern production engineers including the nature and content of their professional competencies. In addition to the familiar characteristics of the specific qualifying requirements for the professional competence of the future engineer, it is no less important today for future engineering specialists to possess the following knowledge, skills, abilities, and personal qualities.

\section{Knowledge:}

- The tendencies, directions, and development prospects for fields of industry require scientific knowledge;

- Selection methods, including obtaining scientific knowledge according to actual production needs

- Technologies to introduce scientific ideas and industry developments

- The commercialization of scientific research

- Methods for engineering creativity

- Content and methods of work culture of engineers

- The legislative, legal, and regulatory frameworks for industrial, engineering activity

- Environmental requirements for production organization in relevant industries

- The psychology of interpersonal and collective relationships in the workplace as well as the culture of business communication

- Methods for professional and personal self-development.

\section{Skills:}

- To respond to production needs in terms of scientific knowledge and development, to select, analyze and forecast possible economic consequences and innovation results

- To produce independent scientific knowledge, generate ideas, design, and manufacturing processes

- To plan and organize the implementation process for scientific ideas and developments

- The ability to carry out technical and economic calculations and to determine the commercial benefits of innovation;

- To utilize engineering creativity, including effective methods for technical and engineering creativity

- To make decisions within a framework about legislative, legal and regulatory framework of the industrial, engineering activity

- To adopt environmentally valid production decisions 
- To use computers and information technology

- To carry out scientific and technical analysis, planning, organizing

- To work with technical, economic, legal, and environmental information sources

- To create a favorable psychological climate and to build competently relationships with colleagues.

\section{Abilities:}

- To adapt to the rapidly changing conditions of production

- To have technical thinking and engineering creativity

- To be able to have effective communication and teamwork with employees in the workplace

- Scientific and technical analysis and forecasting of current and potential development prospects of production

- To be able to carry out constructive professional dialogue in multiple languages (Kazakh, Russian, English, etc.).

- Technical and technological skills, legal and environmental thinking

- To be open to constant self-improvement and self-development of professional and personal qualities

- To have professional deformation.

The personal qualities of engineers in this new formulation should include:

- Professional mobility

- A general flexibility of thinking

- Creativity.

At the same time, analysis of existing experience in engineering education reveals a number of issues that will determine the formation of a specialist according to the expectations of market needs. Some of these are selected and characterized here:

1. The problem of the development of an engineering education with the level of economic, scientific, technological, social, and cultural societal development. Colleagues from universities that receive the highest ratings on the basis of international accreditation criteria might claim that their engineering training is "in step with the times. "This remains a very controversial issue, however, because education cannot always respond to the needs of a fast-growing and rapidly changing world. Education prepares specialists mainly by simulating the conditions of an actual production process, the future professional activity of students. These are, however, specially created conditions of professional knowledge. It is important to determine, whether, or not, study in a higher educational institution (it is not the actual production, which is sometimes also behind the development of the science) is not competitive. The science offers new ideas and development and production masters them on the basis of their capabilities (financial, logistical and human resources). The content of the university training of the future engineer reflects existing production conditions and some possible prospects for their development. 
One step to solving problem is education through research activities. Engineering students not only learn the tools and technologies of production, in use now, but also those capacities which are expected to come online in the near future. Students' lessons carries out in laboratories and workshops, where the latest scientific ideas and development of scientists - university professors are tested. These laboratories are equipped with or have at least some elements of technique and technology of the future.

Our studies show that teachers of engineering specialties and students are not unanimous in their opinion about training on the principle of "learning through research activities." Our surveys of students of a number of engineering specialties of M. Auezov South Kazakhstan State University show interesting details: more than 72\% of students believe that they choose production, and therefore it is better to teach them what is now in production, that is, the used equipment, technologies and etc. What awaits them "tomorrow", they learn in production activities, as necessary, that "so everything is constantly changing." The students explain the reason that they do not support the connection between educational and research activities, "the decline in the prestige of a scientist in society," because "they are future production workers, not scientists," "they are more interested in practice."

Another part of the students is convinced that the student needs to combine engineering education with research work, although you will connect your career with production. These are, first of all, students who are actively involved in research clubs participating in department projects. They are convinced that today's industrial engineer should be ready for constant search, invention and innovation, putting forward new, original engineering solutions, for which all training should be accompanied by scientific work.

Although the principle of teaching through scientific activity is declared in university documents, in reality it encounters difficulties. It is also related to the attitude of teachers towards the implementation of this principle. $42 \%$ of the teachers noted that they fully support the principle of "learning through science." However, more than $40 \%$ say that this principle is useful "only in the framework of independent educational and cognitive activities of students and only students who are inclined to scientific work." $18 \%$ of the teachers surveyed are convinced that "there is no need to trouble students who are still engaged in research activities on the basis of professional knowledge and skills."

Such an opposite opinion regarding the principle of teaching through scientific activity and among teachers, in our opinion, is explained by the peculiarities of their pedagogical thinking, motivation and adaptation to innovation. The narrow technical, narrow professional horizons, stereotypes of pedagogical thinking in some of the university teachers of engineering specialties is an obstacle to the development of study programs that work ahead of the curve.

Studying through scientific activity, students take classes in scientific laboratories and workshops, where the latest scientific ideas and developments of scientists teachers of the university are tested. These laboratories are equipped with or have at least some elements of technique and technology of the future. The student interacts with the new machines, equipment and processes used in the experimental mode. 
The student acts as an experimenter of scientific idea, tester of new equipment or technology. Thus, the future engineer is ahead of the modern production engineering, and is preparing for his advance and future, since acquiring valuable skills of the research work.

2. The problem of foundation of engineering education. The pursuit of the short-term commercial benefits often makes the production hopeless. The same applies to engineering education. The academic character of engineering education gives way to a pragmatic approach; it is more of an applied nature. The student is exactly studying what allows him to solve professional problems. Meanwhile, the center of gravity of a mixture of engineering education from fundamental to applied one also affects to the quality of training of future specialists, as it was in the era of the priority of the academic content of education. Among high school teachers, who convince pragmatists dominate opinion on the advisability "of a purely technical education," while minimizing the fundamental education and its humanitarian component.

Today it is important the breadth of thinking, the outlook of an engineer. The specialist cannot be limited by the narrow professional knowledge and skills, as any engineering solution requires a comprehensive, systematic approach. The achievement of genuine fundamental as R.S.Pionova rightly observes, "can be achieved by the fundamental nature of knowledge in all disciplines of the general scientific, general professional and specialized training of students."According to the author, "the main features of the fundamental knowledge and the content of education should be: to ensure the integrity of the perception of the scientific world; disclosure of the facts in the field of professions and specialties; development of the ability to synthesize knowledge from different areas, the formation of interdisciplinary knowledge; ensuring a high level of flexibility, contribute to the understanding and explanation of the essence, the relationship of facts and phenomena from different fields of science and practice" [13].

We believe that it is necessary to revise the philosophy course that the system of engineering education should be aimed at the formation of the fundamental knowledge of future specialists. At the same time, it is necessary to think about the fundamental nature and general professional and special education, development of skills and abilities of the system, a holistic view of the processes under study, skills of analysis, systematization, generalization, abstraction, concretization and generalization of studied technical and technological processes [4].

3. The problem of intellectualization of engineering education. In this case the problem is in the development of methodological culture of an engineer. Developing the ability to analyze their own activities (methodological reflection), possession of methods of scientific knowledge in the various fields of engineering science, the ability of techno-economic modeling, development of intuition and associative thinking - essential elements of intellectualization engineering education. Without these skills and abilities, the modern production engineer cannot promote technical and technological processes. The modern engineer must be intellectual.

4. Development of engineering creativity - not less important problem of engineering education. The adoption of extraordinary technical and economic, technical and technological solutions, introduction of innovation in production, design and 
creation of new industrial tools and technologies require skills to engineering work. Engineering work originates from the creative technical thinking of students. Students' educational research and research activities in the engineering category, sectarian work, academic clubs, competitions and exhibitions are opening new opportunities for the development of technical creativity. It is necessary to ensure that the engineering work engineering students do not have only "learning", cognitive character. Teachers need to organize the work of engineering students with the real industrial impact. Good results give the patent work, participation of students in the examination of scientific ideas and developments. We must move away from the formalities in the implementation of projects and dissertations, which, in fact, have repetitive tasks and calculations every year, wearing a reproductive character. Each thesis must be associated with a creative solution at least a small technical and technological challenges.

In the development of engineering creativity, it is important the formation of students' skills in engineering design. The study of design techniques, technical modeling dealing with the implementation of production tasks, has a positive effect on the formation of future engineering specialist's thinking.

5. Development of ecological thinking of the future engineer. The interaction between a man and nature is becoming complex, and environmental problems in terms of engineering and technology is only compounded. An important constituent of engineering thinking must be ecological thinking today. The valuable relation of the future expert to the nature, his knowledge of the environmental problems and ways of their solutions may be a condition of making the environmental viability of the technical and technological and industrial solutions. We see many consequences of engineering solutions around that are somehow negatively affect the environment. Environmental factor for the engineer has to stand on a par with economic factor in the decision of any engineering solutions.

6. Humanization of engineering education. It is appropriate to note the anthropological approach to engineering education. Engineering knowledge, skills, ability serve for the good of a man and for a man. We cannot do this with one technocratic approach and the one-sided technical and technological expertise. The engineer's human knowledge contributes not only to the overall development outlook, the outlook of the engineer as an intellectual, but also affects his professional activities. Human approach is needed in the system of interaction between the "man-machine". The engineer's humanism is manifested in the "products" of his activities in engineering, technology, organization of production, which requires the participation of people for whom it should be created the most good and safe working conditions.

7. Problems of developing the skills of professional and personal self-development of future engineers. The modern engineer is a self-developing, self-improving specialist. Personal self-development is a necessary condition for growth and professional development engineer. Therefore, it is important to equip future engineers by selfdevelopment and self-improvement skills. They should have skills of goal setting, planning and scientific organization of labor, and ownership of technology time management, improve efficiency, management of emotions, culture, business communication, reflection - all of them must be the subject of special study in the content 
of engineering education. It is proposed to introduce the course "Acmeology" for engineering students, the organization of trainings, meetings with successful people.

\section{Discussion}

In recent years, against the backdrop of changing paradigms of education in general and engineering education, in particular, among practitioners of higher education and scientists, there has been a marked increase of interest in the problems of forming professional competencies. In the practice of engineering education, modular educational programs, curricula and programs are developed taking into account the principles of the competence approach. That is, the aims, objectives of the courses, the expected results of the educational process are formulated specifically in the form of competences of the future engineer.

Meanwhile, like any pedagogical innovation, the competence approach to planning and organizing the educational process in higher education requires scientific and methodological support. The pedagogical practice of engineering education has shown that research, scientific research in this direction is needed. Pedagogical efforts in the introduction of a competence approach in the preparation of a future engineer should be scientifically based.

Many issues of the methodology and theory of engineering activity and engineering education are reflected in the works by N.N. Grachev [9], V.A. Demin [6], S.A. Druzhilov [7], V.P. Shestak [15], N. Almetov, et al [3], White, et al [19], J.Buckley, et al [5], P.Shekhar, et al [14], Korkmaz, et al [10] and others.

Interest in this context is represented by studies of V.V. Kostygina [11], O.A. Garmaeva [8], S.A. Tatyanenko [18], T.V.Silchenko [16], P.V. Stefanenko, et al [17], A.M.Abdirov, et al [1], McGlashan [12] and others.

So, in the article by V.V. Kostygina, the analysis and results of the pedagogical experiment on the formation of the professional competence of the civil engineer in the process of students passing through the training and production practices are presented. The author concluded that teaching and production practice takes the leading place in the process of forming a young specialist. Practice makes it possible to strengthen and develop professional competence as a base for the preparation of a highly qualified graduate of a university a civil engineer.

The analysis of the results of questioning students obtained by V.V. Kostygina gave grounds for formulating a number of the following important points:

- Students of a construction institution have an idea of the future profession and professional competence of the construction engineer, but their ideas reflect, as a rule, the everyday level of knowledge

- The professional orientation of the student's personality is ambiguous, the most obvious is the tendency to receive a large salary, and not to professional competence

- The trend of professional-personal development in the process of passing the practice is revealed in no more than $38 \%$ of cases

- The main motives for passing the practice are fixed such as the desire to gain credit and professional skills 
- Most undergraduates consider themselves to be an average level in terms of the formation of professional competence

- Most of the students in the university - representatives of building dynasties [11].

In O. Garmaeva's work the conceptual bases of realization of the competence approach in the Russian education system are explored, the strategies of interaction with the world education system, the main aspects of forming the professional competence of future engineers are determined [8].

Professional competence is considered by the author as "readiness to perform professional activities. The concrete meaning of this readiness is expressed in the ability to solve problem situations arising in professional activity ". We are in solidarity with the author in the sense that each engineering specialty requires the development of its competence, its essence, features and structuring.

O. A Garmaeva formulated the following general requirements for competence training:

- In competence training, the role of knowledge changes, since here we are talking only about those that are necessary for the formation of this professional competence

- The analysis of the results of educational activity is changed in competence training: the level of professional competence is assessed, rather than the level of knowledge

- Training methods should be professionally oriented.

As for the formation of the professional competencies of the future engineer, according to the author preference is given to problem training, but also personality-oriented methods, reflexive technologies [8].

In the thesis of V.A. Tatyanenko, the problem of the formation of professional competence of the future engineer in the process of teaching mathematics in a technical college. The author puts forward and substantiates the idea that "the formation of the professional competence of the future engineer in the process of teaching mathematics in a technical university is possible if the goals of their education, development and upbringing in the process of teaching mathematics are correlated with the components of the professional competence of the future engineer" [18].

The author developed requirements for the method of teaching mathematics in a technical university, aimed at forming the professional competence of a future engineer. In the study, the goals of teaching, developing and educating students in the process of teaching mathematics are grounded and designed on the basis of correlation with the components of the professional competence of the future engineer. Also, educational tasks adequate to the projected goals have been developed and methodical methods of their use in teaching mathematics to students of a technical college have been selected.

Interest from a scientific and practical point of view was discussed by V.A. Tatyanenko who addressed the components of the methodology used for teaching mathematics in a technical university aimed at forming the professional competence of the future engineer, and include: 
- Categories of learning, development, and upbringing goals correlated with the components of the professional competence of the future engineer

- Educational tasks adequate to the projected goals of education, development and upbringing

- Methodical approaches for incorporating projected learning tasks into the use of problematic, collective, group, visual methods, the method of mathematical modeling in the process of teaching mathematics [18].

In the monograph T. Silchenko the problems of forming the professional competence of an engineer in the conditions of transition from an industrial to a postindustrial society are considered. The author made an attempt of the theoretical and methodological substantiation of one of the variants of designing the vocational training of graduates of higher educational institutions, which train engineers who are oriented towards the competence of the approach. The practical ways described by the author for revealing the level of the formed competence at the graduate of the university are of interest [16].

In the research work of P.V. Stefanenko and P.V. Kushnirenko are studying the professional competence of a mining engineer. The authors give a comprehensive analysis of the content of the professional activities of a mining engineer from the point of view of a competence approach. The basic and specific competencies of the mining engineer will be identified, which is the benchmark for training the future mining engineer in higher education institutions [17].

A.M. Abdirov and T.K. Nurmuhamedova [1] have researched the problems of engineering competency formation for engineers of the agro-industrial complex. N.Sh. Almetov, G.K. Otarbayeva, T.B. Ashirbekova [2] consider the issues of implementation of the competence approach in the context of the formation of the foundations of engineering creativity among students of a technical university.

Thus, the study and analysis of literature on the problem of forming engineering competencies for future engineers in the university allows us to draw such conclusions:

- Engineering activities should be a key reference point for determining the basic and professional competencies of the future engineer, modeling the process of their formation in the conditions of training in higher education

- Currently in the study of the problems of implementing the competence approach in the training of future engineers, more attention is focused on studying the specific competencies of the future specialist in specific engineering professions

- When teaching general technical disciplines, the goals of their education, development and upbringing in the process need to be correlated with the components of the professional competence of the future engineer, while strengthening the professional orientation of general engineering education on the basis of a competence approach.

Meanwhile, the study of the competence approach in the preparation of the future engineer is still at an early stage. It is necessary to research the answers to many issues of engineering education, namely: 
- Determination of factors and conditions affecting the production processes, and the level of development of the professional competencies of engineers in various industries

- Definition of generalized knowledge, skills, abilities, abilities and personal qualities important for the proficiency of specialists in engineering, which can be easily translated into the conditions of specific engineering training of a future specialist in a specific engineering industry

- Highlight problems of engineering education in terms of implementing a competence approach. Formation of professional competencies and competences of the future engineer should be carried out in a bilateral, mutually complementary area: "from engineering to engineering education", and "from engineering education to engineering activities".

\section{Conclusion}

Engineering education from the perspective of the implementation of the competence approach requires further improvement. The analysis of the content of engineering education through the prism of competence-based approach allows us to highlight the range of problems of training future engineers in high school, organizational and pedagogical solution of them creates new potential opportunities for quality improvement of final characteristics of the university graduate - the engineer of the new formation.

Competence approach to engineering education is integrated with its fundamentalization, humanization, intellectualization, ecologization, strengthening creative and acmeologic orientation.

Qualification characteristics of the future engineer, in our opinion, today are required a fundamental renewal taking into account the position of engineering education, based on the final result. Interval and final results of engineering education are expressed in the competencies of future professionals who reflect his general culture, general professional and special knowledge, skills, abilities and professional and personal qualities.

\section{Acknowledgement}

Authors are grateful to M.Auezov South Kazakhstan State University, Silkway International University, H.A. Yasawi International Kazakh-Turkish University, Korkyt Ata Kyzylorda State University and Kazakhstan National Pedagogical University for the support to carry out this research.

\section{$7 \quad$ Ethics}

The authors would be responsible for any issues that may arise after the publication of this manuscript. 


\section{$8 \quad$ References}

[1] Abdirov, A.M., Nurmuhamedova, T.K. (2009), Forming the professional competence of the engineering specialists. Vestnik PGU, 4, 9-15

[2] Almetov, N. Sh., Otarbayeva, G.K., Ashirbekova, T.B. (2017). Formation of technical specialties students.ICS - 2017.IV International conference" Industrial technologies and engineering, Shymkent, 150-155.

[3] Almetov, N., Zhorabekova, A., Bolysbayev, D., Buletova, L., Kornilko, I. (2017). Professional Teaching Competence in the Aspect of Multilingual Education. Espacios, 38 (45), 26

[4] Almetov, N.S., Arymbaeva, K.M. Pedagogy: study guide for candidates for a master's degree of scientific and pedagogical specialties. Shymkent, 2014

[5] Buckley, J., Seery, N. \& Canty, D. (2019). Spatial cognition in engineering education: developing a spatial ability framework to support the translation of theory into practice. European Journal of Engineering Education, 44: 1-2, 164-178, https://doi.org/10.1080/ 03043797.2017.1327944

[6] Demin, V.A. (2000). Professional competence of a specialist: the concept and types, Standards and monitoring in education, 34-42.

[7] Druzhilov, S.A. Fundamentals of the psychology of professional activity of electrical engineers. Novokuznetsk, 1999.

[8] Garmaeva, O. (2013). Formation of professional competence of future engineers. Bulletin of the Buryat University, 15.

[9] Grachev, N.N. Psychology of Engineering Labor: Proc. Allowance. Moscow: Higher School, 1998.

[10] Korkmaz, Ã., KösterelioÄŸlu, M., Kara, M. (2018). A Validity and Reliability Study of the Engineering and Engineering Education Attitude Scale (EEAS). International Journal of Engineering Pedagogy (IJEP), 8 (5): 75-88. https://doi.org/10.3991/ijep.v8i5.8667

[11] Kostygina, V.V. (2009). Formation of professional competence of a civil engineer in the process of training and production practices. Integration of education, 4.

[12] McGlashan, A., Moon, C., Kim, W. (2018). Engineering Education in an Integrated Setting. International Journal of Engineering Pedagogy (IJEP), 8 (3): 17-27.

[13] Pionova, R.S. Pedagogy of higher school. Minsk: Higher School, 2005.

[14] Shekhar, P., Prince, M., Finelli, C., Demonbrun, M. \& Waters, C. (2019). Integrating quantitative and qualitative research methods to examine student resistance to active learning, European Journal of Engineering Education, 44:1-2, 6-18, https://doi.org/10.1080/ $\underline{03043797.2018 .1438988}$

[15] Shestak, V.P. (2015). Engineering potential of fundamental science. Higher education in Russia, 12, 13-21.

[16] Silchenko, T.V. Professional competence of a modern engineer, Monograph. Krasnoyarsk: Siberian Federal University, 2011.

[17] Stefanenko, P.V., Kushnirenko, E.N. (2015). Definition of engineering competence of the mining engineer. Bulletin of the Civil Defense Institute of Donbass, 2 (2), 62-67.

[18] Tatyanenko, S.A. Formation of professional competence of the future engineer in the process of teaching mathematics in a technical college. (Dissertation). Tobolsk, 2003.

[19] White, C., Uhomoibhi, J. (2018). Data Visualization in Engineering Pedagogy through Determination of Colour Variance in Contaminated Grass Samples. International Journal of Engineering Pedagogy (IJEP), 8 (5): 4-18. https://doi.org/10.3991/ijep.v8i5.8142 


\section{Authors}

Negmatzhan Almetov is a Pedagogical Sciences Doctor, Professor of the Department of General Pedagogy and Musical Education, M. Auezov South Kazakhstan State University.

Ainur Zhorabekova is a PhD, Associate Professor of the Department of Sport and General Educational Disciplines at International University of Tourism and Hospitality.

Ibragim Sagdullayev is a PhD, Senior Teacher of the English Philology Department at H.A. Yasawi International Kazakh-Turkish University.

Zhanar Abilhairova is Pedagogical Sciences Candidate, Acting Associated Professor of the Department of Pedagogy and Teaching Methods at Korkyt Ata Kyzylorda State University.

Kholidin Tulenova is a PhD, Senior Teacher of the Department of Physical Education at S. Seifullin Kazakh Agrotechnical University.

Article submitted 2020-03-02. Resubmitted 2020-09-12. Final acceptance 2020-09-12. Final version published as submitted by the authors. 